\title{
Co-operative Led Micro-Disaster Management: A New Model for South Asia
}

Dr. Jyoti Koirala, Tribhuvan University - Kathford International College of Engineering and Management Dr. Suman Acharya, Central Bank of Nepal / Tribhuvan University - National Law College

We also acknowledge the contributions received from academics and researchers during the various consultative meetings. We are grateful to Dr. Nimananda Rijal, Kathmandu University - School of Education; Dr. Madhusudan Neupane, Tribhuvan University - Bajra International College and Dr. Motiram Phuyal, Tribhuvan University - Kutumba College of Management and Humanities Studies.

The study was carried out with the support from Unique Star Education Foundation (USEF), Putalisadak, Kathmandu, Nepal.

\begin{abstract}
:
The main purpose of this study is to come up with new concept and models for disaster management in terms of preparedness, response, and recovery through discussion and exploration. The overall aim of the study is to identify the needs and gaps of preparedness, response, and recovery of 2015 Earthquake and make recommendation for effective preparedness, response, and recovery for Nepal and South Asia. The study identifies a huge gap in preparedness, response, and recovery and highlights the need of introduction of concept of new model of cooperative disaster management at microlevel for better preparedness, response, and recovery. This study also highlights that existing approach of disaster management policies cannot sustain for longer period at the community level and it is high time to come up with new models that community people will feel the impact. The models and concept been discussed in the paper.
\end{abstract}

\section{INTRODUCTION:}

The definition of disaster is occurring of unexpected, catastrophic event that badly disrupts the operation of a community or society causing social, economic, and environmental losses ${ }^{1}$. This is the reason disaster managers need to evaluate the impacts of disasters with reference to their own local circumstances ${ }^{2}$. The disaster can be $\bullet$ Earthquake, $\bullet$ Volcanic eruption, $\bullet$ Tsunami, $\bullet$ Tropical cyclone (typhoon, hurricane), $\bullet$ Flood, $\bullet$ Landslide, $\bullet$ Bushfire (or wildfire), $\bullet$ Drought, $\bullet$ Epidemic, $\bullet$ Major accident, and $\bullet$ Civil unrest ${ }^{3}$.

\footnotetext{
${ }^{1}$ IFRC (2020). What Is A Disaster? - IFRC. Retrieved 25 August 2020, from https://www.ifrc.org/en/what-we-do/disastermanagement/about-disasters/what-is-a-disaster/>

${ }^{2}$ Asian Development Bank (2020). Retrieved 25 August 2020, from https://think-asia.org/bitstream/handle/11540/5035/disastermanagement-handbook.pdf?sequence=1

${ }^{3}$ Asian Development Bank (2020). Retrieved 25 August 2020, from https://think-asia.org/bitstream/handle/11540/5035/disastermanagement-handbook.pdf?sequence $=1$
} 
Nepal is one of the South Asian Countries surrounded by Himalaya region. It occupies a total area of 147,181 -kilometer square. The west to east length of it is $885 \mathrm{~km}$ and its breadth of North and South area ranges from $145 \mathrm{~km}$ to $241 \mathrm{~km}$. Likewise, Large portion of the area has been covered by hills and mountains. It has also plain flat region. ${ }^{4}$

Because of the geographical location, Nepal is likely to prone to natural disaster. It may cause internal and external displacement along with the human and proprietary casualty. It may adversely harm ecosystem of the region.

\section{RATIONALE AND OBJECTIVE OF THE STUDY}

On Saturday, April 25th, 2015 at 11:56 hrs, local time, a magnitude of 7.6 earthquakes stuck the Federal Republic of Nepal with an epicenter located approximately 76 KM northwest of Kathmandu, in Gorkha District. Approximately 9,000 people had lost their lives and more than 22,000 people were injured and one third of the population have been impacted directly. Huge damaged has occurred. It is important to understand the role Government and its disaster management in Gorkha Earthquake 2015 for understanding the effectiveness of the government and non-government agencies in preparedness, response, and recovery.

The study tries to find out level of government response in terms of preparedness, response, and recovery and how the general people felt at community level. Based on the result, the studies suggest the new model for disaster management in South Asia.

\section{CONCEPTUAL FRAMEWORK AND DISASTER MANAGEMENT POLICY}

Nepal, located at central of Himalayas range, is largely disaster-prone area because of tectonic plate and high mountains. It may face flood, landslides, earthquake and alike. Earthquake has hardest hit from time and again over the period of time. In such incidence, Nepal has to follow cooperative model of micro disaster management.

Figure 1: Conceptual Framework for Disaster Management Mechanism

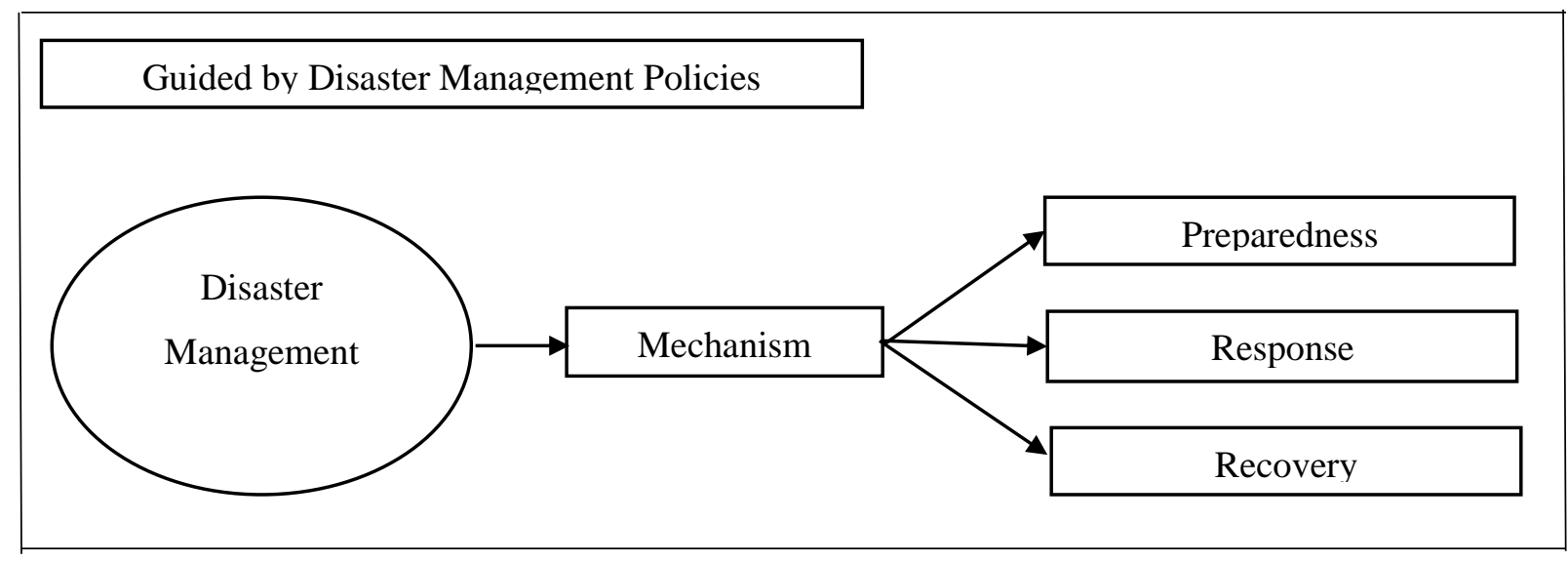

Understanding the disaster management can only be possible through understanding the preparedness, response, and recovery guided by disaster management policy as shown in figure 1 .

${ }^{4}$ GPS (2020). Retrieved 25 August 2020, from http://web.gps.caltech.edu/ avouac/nepal_trip/geography.htm 
The different methods used for this study is understanding the disaster management by gathering information on people's experience and understanding of local community during the earthquake through mixed methodology of semi structured questionnaire. This is done to understand how the mechanism is functioning after the 2015 Gorkha Earthquake of Nepal. This study considers the ethical implications that need to be considered for possible harm.

\section{DATA PRESENTATION AND ANALYSIS}

This study is based on testing of hypothesis whether the disaster management mechanism is functioning properly or not. The mechanism has been analyzed in three forms based on Preparedness, Response and Recovery mechanism. All the variables related to preparedness, response and recovery has been further classified for depth analysis. There seems to be the significant relationship between the preparedness, response, and recovery mechanism and disaster management. Since the $p$-value is accepted at 5 percent level of significance, the hypothesis "The Disaster Management Mechanism is not functioning properly" is accepted, which shows that the Preparedness, Response, Recovery and Reconstruction mechanism is not functioning properly during the time of Gorkha Earthquake 2015.

The local people felt that the preparedness, response, and recovery is not functioning properly. This means that respondents do not feel that there is preparedness for disaster from government level, there is weak response from government level and recovery plan of government is also very weak.

\section{MAJOR ISSUES RAISED FROM THIS ANALYSIS}

Data presentation and analysis shows that preparedness, response, and recovery is not functioning properly in Nepal. Millions of amounts is spend each year in the name of Disaster Management but if disaster management mechanism is not functioning, if the general public do not feel that there is proper preparedness, response, and recovery happening then what is the use of such spending? What is the use of governmental and non-governmental partners following international practice of HYOGO and SENDAI Framework, if our models are not functioning in the right direction? This is true that both the number of natural hazards, and direct and indirect mortality and morbidity increase every year ${ }^{5}$ but the understanding has remained the same throughout the world.

\section{FUTHER VERBATIM INTERVIEW AND ANALYSIS}

The study makes the further analysis of various issues raised from the conclusion of this study for purpose of getting the solution to the issues raised. For this, Verbatim Interview has been done to the experts working in the field of disaster management, media, legal, community development, medical, and social workers on how the people-oriented disaster management should be there. The further

a) Majority of experts agree that not only the Man but also the Women population, not only educated but also non-educated population, not only landlords but also the small farmers, not only Upper Caste but also the Lower Caste population, not only Strong but also Weak population, not only the Rich but also the Poor population, not only the native but also immigrant population should feel that the disaster Management activities are there in their area. They should feel that preparedness, response, and recovery activities are there and happening in their area. Until and unless people do not feel at micro level, spending the huge money at macro level is useless.

b) Majority of experts feel that when the major disaster happens, population are not worried about their House, Car, Real Estate, Cash, Gold, Facilities, Assets but only worried about life. It can be life

5 Goniewicz, K.; Burkle, F.M. (2019). Challenges in Implementing Sendai Framework for Disaster Risk Reduction in Poland. Int. J. Environ. Res. Public Health 
of family and close people. Managing disaster should be guided towards saving the life at first level and again saving the other facilities at the second level. This first level and second level can only be understood by the local community and people.

c) Majority of experts agree that Categorization for formal, semi-formal and informal mechanism should be there in the country for managing the disaster. Informal is the self-help group of people with similar interest which can be family or friends or neighbors or community people. Similarly, semi-formal can be participation from people and government or non-governmental led group and finally formal can be fully government or non-government oriented. This will bring sense of responsibility from local level.

d) Majority of experts agree that micro-disaster management is the more of informal and semi informal led management of preparedness, response, and recovery. Subsidy in management of disaster through cooperative lead group will be more effective. This brings the self-responsibility to the community and proper utilization of money and resources will be there. This will bring control over the uncertainty and emergencies.

e) Majority of experts agree that reaching the ultra-poor and neglected society or population will minimize the issues in disaster management. Preparedness, response, and recovery will be more effective as compare to the central level intervention.

f) Majority of experts agree that there are many challenges in cooperative lead micro disaster management. Challenges may be in terms of inadequate monitoring of activities, possibility of diversion of fund, poor disaster management literacy, no such research earlier on this, geographical issues etc are always there.

g) Majority of experts agree that future of cooperative lead micro disaster management is more effective approach than any other approach. Use of cooperative group in providing the knowledge about the climate change, flood management, fire management, landslides, bushfires, irrigation, drought management will bring some level of self-responsibility.

h) Majority of respondents feel that Government and Non-government should focus on increasing the human wellbeing in rural and remote area to give the sense of better preparedness, response, and recovery at root level. It is necessary to work and implement on this concept.

\section{COOPERATIVE LED MICRO-DISASTER MANAGEMENT MODEL}

Cooperative is an association of individual people who are voluntarily united with common objective. When the common objective of community people is towards the management of disaster in the local level then that leads to better preparedness, response, and recovery. Majority of the respondents in this study has agreed this. The word Micro refers to small, when the small groups are together in managing the disaster will lead to the greater step.

Cooperative led Micro-Disaster Management is the new concept developed targeted to poor who are at remote places and more vulnerable to disaster management. The concept is that it should be globally recognized as effective tools for disaster reduction. This will lead to better climate control and better preparedness, better response, better recovery in days to come. This is the paradigm shift in the management of disaster for future. This need has been reflected when the respondents experienced the poor disaster management preparedness, response, and recovery. 
Figure 2: Informal, Semi Formal and Formal Type of Disaster Management Mechanism created based on Verbatim Interview

- Cooperative Groups Consist of similar friends, families, or supporters.

\section{Informal}

\section{Semi-formal}

-Partially supported

by Government, Non

Governmental or

Development Parters
-Fully Supported by Government, Non Governmental or Development Parters

\section{Formal}

For localization of disaster management to bring the feelings of preparedness, response, and recovery at ground level the study proposes the figure 2 type of model. This model been derived from based on verbatim interview with experts.

Figure 3: Informal Cooperative Type of Disaster Management based on this study
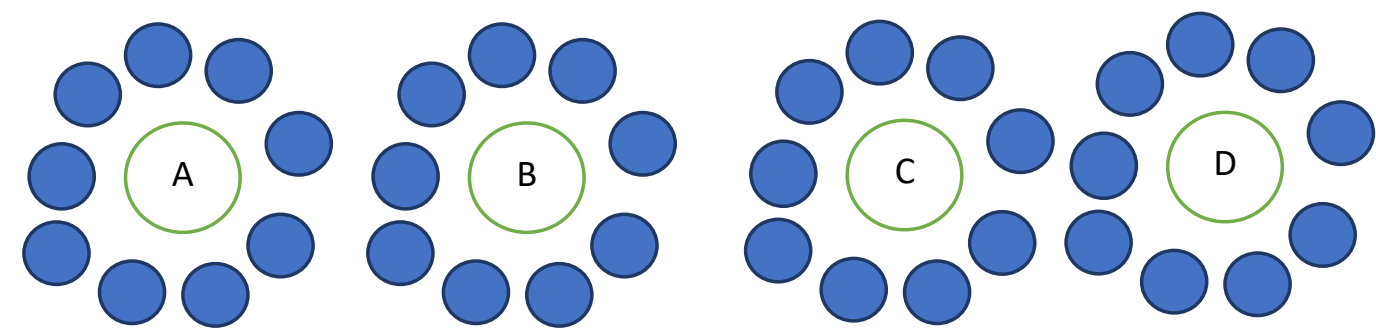

Note: $A, B$, and $C$ in figures are Region or area. The concept is that to form a small cooperative group in high disaster-prone area.

The purpose of this micro- disaster management through cooperative model gives to greater support to the livelihood and healthcare in terms of preparedness, response, and recovery which will have significant effect

management from the grassroot and will bring significant role in reducing the gap that been neglected and remote group.

The figure 3 shows that one area or region is divided into many groups in cooperative style which will working in solving the issues related to disaster management. When one group can not control over the disaster, the other group will also support. Activation of such cooperative mechanism of micro disaster management will give wider control and feeling of preparedness, response, and recovery will be there.

\section{IMPLICATION OF THIS COPERATIVE LED MICRO DISASTER MANAGEMENT MODEL}


This model will somehow mitigate the issue of poor preparedness, poor response, and poor recovery faced by the community people. This will give better understanding of preparedness, response, and recovery. The public awareness and public education can be increased in better way. The group can be utilized in providing the special knowledge on revival economy, empowering the individuals, communication and transparency, evacuation to safe place, emergency shelter, search and rescue mechanism, medical assistance and support, relief disbursement, surveillance of possible disaster human and natural induced disaster, debris management, resettlements, better response etc. In the first phase, this can be implemented in few places as pilot survey and experience need to be collected and spread in other places too.

Natural disaster basically not controllable in nature and for this our society is not prepared for control leading to huge damage to society and nation. Both formal and informal sectors are affected. The controlling mechanism should be developed in such a way that respondents need to feel some level of preparedness, response, and recovery.

The case study of Gorkha Earthquake shows that respondents did not feel the level of preparedness, response, and recovery from governmental and non-governmental level. The study further makes the analysis through expert interview methods and tries to find out how the issues can be solved. The study makes the further analysis of various issues raised from the conclusion of this study for purpose of getting the solution to the issues raised. For this Verbatim Interview has been done to the experts working in the field of disaster management, media, legal, community development, medical and social workers on how the people-oriented disaster management should be there.

This model will not only be valid for Nepal, will be effective in South Asia due to similar nature. The increased frequency of disaster and its intensity is trending day by day. Despite of this increment, awareness and understanding on disaster has not yet been found. It is necessary for the policy makers and responsible people to increase better resilience through cooperative led micro disaster management model. Engaging the local people in disaster management and climate change will help to control the situation better due to self-led approach. 


\section{References}

Lewis J. (1999). Development in disaster-prone places: studies of vulnerability, IT Publications, London

MERDP (1998). Efforts at participatory rehabilitation and the role of community participation consultants, Maharashtra Earthquake Rehabilitation Documentation Project, Report No. 4, Government of Maharashtra Publications, Mumbai, India

Middleton N. and O'Keefe P. (1998). Disaster and development: the politics of humanitarian aid, Pluto Press, Chicago, USA

Olorunfemi A. R., Awotayo F., Tunde, A., \& Usm, B. (2013). Disaster Risk Management and Social Impact Assessment: Understanding Preparedness, Response, and Recovery in Community Projects. Environmental Change and Sustainability.

Olorunfemi, F, \& Raheem, U. A. (2007). Urban Development and Environmental Implications: The Challenge of Urban Sustainability in Nigeria. The Australasian Review of African Studies Volume XXVIII 2006/2007

Olshansky, R. B., \& Johnson, L. A. (2010). Clear as mud: Planning for the rebuilding of New Orleans. Chicago, IL: American Planning Association.

Parasuraman S., and Unnikrishnan P. V. (2000). Disaster response in India: an overview, In: India Disaster Reports: towards a policy initiative, Oxford University Press, New Delhi, India, pp. 3-20

Philippine NLUC (1992). National Physical Framework Plan, 1993-2022. NLUC, National Economic and Development Authority, Manila.

Quah, D. (1993). Empirical Cross-Section Dynamics in Economic Growth." European Economic Review 37: 426-34.

Rahman, Atiur, and others (2000). The Budget and the Poor. Study commissioned by the Institute for Development Policy Analysis and Advocacy, Proshika, and conducted by Shamunnay. Dhaka: University Press.

Velpuri, M., \& Pidugu, A. (2016). Big Data for Disaster Management and Real estate Management in Smart Cities.

\section{Contact:}

Author can be contacted at get2jyoti@gmail.com or sumanacharya@gmail.com 